\title{
Quit smoking behaviours and intentions and hard-core smoking in New South Wales
}

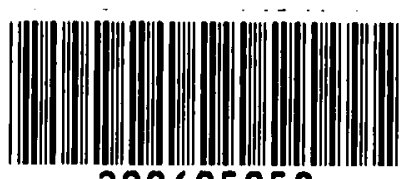

\author{
Raoul A. Walsh, Christine L. Paul, Flora Tzelepis and Elizabeth Stojanovski
}

\begin{abstract}
Introduction
The promotion of smoking cessation remains a crucial goal of tobacco control efforts. ${ }^{1}$ To this end, considerable effort has been expended in the development of smoking cessation clinical practice guidelines and recommendations. ${ }^{2,3}$ Mass media-driven anti-smoking campaigns in the community have also been implemented to encourage smoking cessation. ${ }^{4,5}$ For example, in Australia, after a period of little Commonwealth-funded antismoking activity for much of the 1990s, a new national mass media campaign was launched in $1997 . .^{5}$ This campaign appeared to stimulate a renewed decline in adult smoking prevalence. $^{5}$

In order to inform the development of further smoking cessation initiatives, it is important to assess the quitting behaviours and attitudes of current and former smokers including their reasons for attempting to quit.6,7 The Stage of Change construct has frequently been used to measure readiness to quit smoking. ${ }^{7,8}$
\end{abstract}

\begin{abstract}
However, in recent years this model has been subject to increasing criticism related to questionnaire validity ${ }^{9}$ and predictive ability. ${ }^{10,11}$ Another model, known as the quitting continuum, has been demonstrated to predict progress towards successful smoking cessation better. ${ }^{10}$ The quitting continuum combines three main domains: addiction level, quitting history, and intention to quit. ${ }^{12}$ Consumption of 15 or more cigarettes per day constitutes high addiction. Quitting history involves four categories: quit attempts of less than one day, 1-6 days, or one week or longer in the past year, and of one year or longer since becoming addicted. Intention to quit focuses on whether the smoker is contemplating quitting in the next six months. It has been recommended that the quitting continuum could be used to monitor intervention effects and to develop tailored interventions. ${ }^{12}$ However, no published Australian data document the distribution of smokers on the quitting continuum. Another issue being debated in the smoking cessation field
\end{abstract}

\section{Abstract}

Issue addressed: Quitting intentions and behaviours of smokers require monitoring. In particular, assessment of the distribution of smokers on the quitting continuum and of the proportion of hard-core smokers has implications for the design of future quit campaigns.

Methods: Cross-sectional survey of 1,509 persons ( $74.4 \%$ consent rate) randomly selected from the New South Wales Electronic White Pages. 1,431 respondents were eligible (aged 18 and over).

Results: Current smokers comprised $19.1 \%(n=274)$ and former smokers $28.0 \%(n=400)$. Sixty-one per cent of current smokers had quit for at least one day in the last year and $67.1 \%$ were in the intermediate or advanced preparation levels of the quitting continuum. Half of the smokers $(46.7 \%)$ recalled receiving cessation advice during a past-year medical visit. Sixty-four point five per cent $(64.5 \%)$ of smokers and $63.4 \%$ of former smokers reported no use of assistance in their quit attempts. Five point five per cent (5.5\%) of smokers aged 26 and over met the hard-core criteria.

Conclusion: Most smokers want to quit but when making a quit attempt do not use proven, effective strategies. Relapse rates are high in the immediate post-cessation period.

Key words: Smoking cessation, quitting, quitting continuum, hard-core smoking, survey.

Health Promotion Journal of Australia 2006:17:54-60

\section{So what?}

In addition to motivating smokers to stop, quit campaigns must encourage greater medical advice-giving and more use of effective cessation aids. Older smokers require increased intervention emphasis. Hard-core smokers represent a small proportion and programs do not require major reorientation to target this group. 
concerns the existence of a group of hard-core smokers who are especially resistant to giving up smoking. ${ }^{13,14}$ Debate centres around the related issues of the size and significance of this group, and how hard-core smoking should be defined and treated. ${ }^{15,16}$ To date, no estimates of the prevalence of hardcore smokers in Australia have been published.

Therefore, the objectives of the present study of randomly selected New South Wales adults were:

1. To assess smoking and quitting behaviours and attitudes of current and former smokers, as well as intentions to quit among current smokers.

2. To document the proportions of smokers at different levels of the quitting continuum and to compare these proportions with those found in a Californian sample.

3. To estimate the prevalence of hard-core smokers and to contrast this with Californian ${ }^{14}$ and English ${ }^{17}$ estimates, derived using the same methodology.

\section{Method}

\section{Design and setting}

The study was conducted as part of a larger omnibus community survey of cancer-related issues. Telephone numbers of 3,227 households were selected from the New South Wales (NSW) Electronic White Pages and an information letter mailed to the corresponding address. Telephone contact was made in the four weeks following the initial letter. Of persons in that household aged 15 years and over, the one with the next birthday was asked to participate. Only those aged 18 years and over were eligible to answer the smoking-related questions. Approval for the study was given by the University of Newcastle Human Research Ethics Committee.

\section{Participants}

Smoking status was identified according to the method recommended by an Australian expert group. ${ }^{18}$ Those who had smoked at least 100 cigarettes in their lifetime but were not smoking at all now were defined as former smokers. Those who had smoked at least 100 cigarettes and were still smoking daily or occasionally were defined as current smokers.

\section{Questionnaire}

The questionnaire contained sections for both current and former smokers. Questions included issues such as smoking behaviours, quit intentions, past cessation activity, reasons for quitting/quit attempts, exposure to medical cessation advice, and use of counselling, self-help materials and nicotine replacement therapy (NRT). Many questions replicated those in the California Tobacco Surveys. ${ }^{12}$ In the case of current smokers, the focus of most questions was on the preceding 12 months. Of former smokers, only those who had quit in the previous two years were asked questions about their use of counselling/self-help materials and NRT.

\section{Analysis}

All analysis was undertaken using SAS (Version 8.02, (C) SAS Institute Inc. 1999). Associations between smoking intake, quitting intentions of smokers and gender were assessed using chi-square analyses, and a $t$-test was used for quit attempt duration. A Kaplan-Meier estimate of the survivorship function was used to graphically depict the distribution of the duration of longest quit attempt in the past 12 months. Separate backward stepwise logistic regression procedures with an entry level of 0.25 were used to identify demographics that were statistically significantly associated with having made a quit attempt in the last year and with high levels of the quitting continuum at the 0.05 significance level. Odds ratios and $95 \%$ confidence intervals were reported for variables in the final model. The prevalence of NSW smokers in each category of the quitting continuum was compared with the associated prevalence of Californian smokers using chi-square tests. Finally, the proportion of hardcore smokers was calculated and this proportion was compared with the associated prevalence in California and England using chi-square tests.

\section{Results}

\section{Sample}

Of the 3,227 telephone numbers selected, 768 were ineligible (non-residential, disconnected, fax numbers outside NSW, or did not contain anyone with sufficient English to complete the interview), 431 were not contactable, 519 refused to participate or did not complete the interview, and 1,509 gave complete interviews, giving a response rate of $61.4 \%(1,509 / 2,459)$ and a consent rate of $74.4 \%(1,509 / 2,028)$. The demographic characteristics of the 1,431 respondents eligible to answer the smoking questions were compared with the characteristics of the NSW population from the 1996 Census $^{19}$ and with the main tobacco use survey in Australia. ${ }^{20}$ Some minor differences were found, but overall the sample was broadly comparable with the NSW population and Australian smokers.

\section{Smoking prevalence, cigarette intake and age of initiation}

Of adult respondents, 274 (19.1\%) were classified as current smokers (16.9\% daily, $2.4 \%$ occasional) and $400(28.0 \%)$ were classified as former smokers.

Daily smokers averaged 15.9 cigarettes per day (males 17.2, females 14.6). Significantly more males $(63.7 \%)$ than females (47.6\%) smoked more than 15 cigarettes per day $\left(\chi^{2}=5.59\right.$, $p=0.02$ ). Occasional smokers averaged 4.2 cigarettes on the 
days they smoked (males 3.3, females 4.9). Among all current smokers, the mean age at which regular cigarette smoking started was 18.0 years ( 17.0 males and 18.9 females).

\section{Quitting behaviours and intentions}

The proportion of current smokers who had ever stopped smoking for a period of at least one year was $32.8 \%$ (males $27.7 \%$, females $37.5 \%$ ).

The quitting intentions of current smokers are detailed in Table 1. There were no significant gender differences.

Current smokers who were also smoking 12 months ago and who had made a quit attempt in that period were asked about the duration of their longest quit attempt. Overall, $61.0 \%$ (males $62.3 \%$, females $59.7 \%$ ) claimed to have quit intentionally for one day or longer in the last year. The mean length of their longest quit attempt was 34.7 days $(95 \% \mathrm{Cl} 26.3-43.1)$ with no significant gender difference (males 34.0, females 35.4 days). The majority (73.9\%) had resumed smoking within one month. Figure 1 depicts a survival curve based on the duration of the longest quit attempt.

A logistic regression analysis was performed to identify whether any of the five demographic variables - age, gender, marital status, educational attainment and living with another smoker - predicted whether a current smoker made a quit attempt of at least one day in the past 12 months.

Only age emerged as a borderline significant predictor $(\mathrm{OR}=0.98,95 \% \mathrm{Cl} 0.96-1.00, p=0.046)$. Each increase of one year in the smoker's age was associated with a reduction in the odds of the smoker making a quit attempt by $2 \%$.

Overall, a retrospective estimate indicated the prevalence of smoking declined by approximately $0.8 \%$ in 12 months.
Table 1: Quitting intentions of current smokers: percentages.

\begin{tabular}{lccc}
\hline $\begin{array}{l}\text { Intention } \\
\text { of quitting }\end{array}$ & $\begin{array}{c}\text { Males } \\
\mathbf{n = 1 3 0} \\
\mathbf{\%}\end{array}$ & $\begin{array}{c}\text { Females } \\
\mathbf{n = 1 4 4} \\
\mathbf{\%}\end{array}$ & $\begin{array}{c}\text { Combined } \\
\mathbf{n = 2 7 4} \\
\mathbf{\%}\end{array}$ \\
\hline Will quit in next month & 10.0 & 18.8 & 14.7 \\
\hline Will quit in next six months & 19.2 & 25.7 & 22.8 \\
\hline May quit but not in next six months & 39.2 & 35.4 & 37.5 \\
\hline Never expect to quit & 19.2 & $\mathbf{1 3 . 2}$ & 16.2 \\
\hline Don't know & 11.5 & 6.9 & 9.2 \\
\hline Refused & 0.8 & 0.0 & 0.4 \\
\hline
\end{tabular}

Although $12.5 \%(n=36)$ of persons who reported smoking 12 months before claimed current abstinence, $2.2 \%(n=25)$ of those who had reported non-smoking 12 months before claimed to be current smokers.

\section{Quitting continuum}

Current smokers who were also smoking 12 months ago were assigned a level on the quitting continuum using the definitions described by Pierce et al. ${ }^{12}$ Table 2 details the level definitions and the proportions of the NSW sample in each level and compares this with the proportions in a random Californian sample of current smokers. ${ }^{21}$ There were significantly more NSW smokers than Californian smokers in the contemplation level $\left(\chi^{2}=10.99, p=0.001\right)$.

A logistic regression analysis was performed to identify if any of the five demographic variables predicted whether current smokers would be in levels $1-3$ of the quitting continuum $(n=84)$ or levels 4-5 $(n=170)$. Only education beyond school certificate level emerged as a significant predictor of being in the

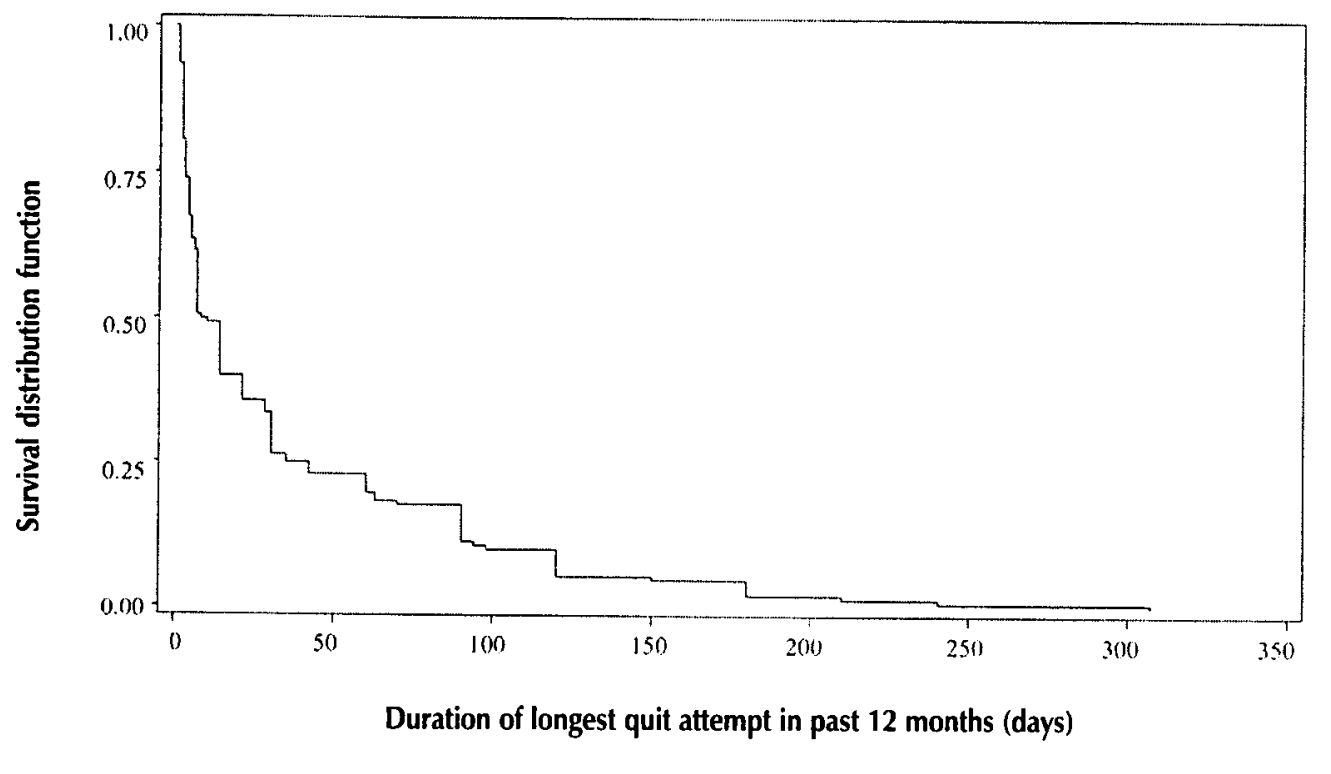

Figure 1: Survival curve based on longest quit attempt. 
intermediate or advanced preparation group (OR=2.17, 95\% $\mathrm{Cl} 1.22-3.86, p=0.008$ ). The other demographic variables age, gender, marital status and living with another smoker failed to predict lower or upper position on the quitting continuum.

\section{Hard-core smokers}

The proportion of smokers who could be characterised as hard-core using the criteria of Emery et al. ${ }^{14}$ was calculated. To classify subjects as hard-core, all of the following six criteria had to be met:

1. They were current smokers.

2. They answered 'yes' to the question "Were you smoking at all around this time 12 months ago?"

3. They had no history of attempts to quit in the past 12 months.

4. They smoked at least 15 cigarettes per day on average.

5. They answered that they "never expect to quit".

6. They were 26 years or older.

Hard-core smokers represented $5.5 \%$ (95\% Cl 3.0-9.2) of current smokers 26 years and older $(n=236)$. Of all respondents over the age of $25(n=1,294)$, the proportion of hard-core smokers was $1.0 \%$.

\section{Quit advice and assistance}

Current smokers who had visited their general practitioner (CP) in the previous year and reported smoking 12 months before $(n=210)$ were asked if a doctor had advised them to stop smoking during that period. Approximately half of this group (46.7\%) recalled such medical advice. More smokers (68.4\%) who remembered receiving GP advice made a quit attempt in the previous year than smokers $(55.4 \%)$ who said they did not receive such advice, although the difference was borderline non-significant $\left(\chi^{2}=3.73, p=0.053\right)$. Current smokers who had
Table 3: Use of counselling, self-help materials and NRT by former smokers who quit in the previous two years and current smokers who reported also smoking 12 months before and who attempted to quit in the previous 12 months: percentages.

\begin{tabular}{lcc}
\hline & $\begin{array}{c}\text { Former } \\
\text { smokers } \\
\mathbf{n = 6 2} \\
\%\end{array}$ & $\begin{array}{c}\text { Current } \\
\text { smokers } \\
\mathbf{n}=\mathbf{1 5 3} \\
\mathbf{\%}\end{array}$ \\
\hline Counselling advice or self-help material & 27.4 & 22.9 \\
\hline NRT use & 27.4 & 32.7 \\
\hline Used NRT and counselling advice/self-help material & 21.0 & 18.3 \\
\hline Used nothing above - unassisted & 64.5 & 63.4 \\
\hline
\end{tabular}

tried to quit smoking intentionally for one day or longer in the past year were also asked whether they used counselling advice or self-help material during their longest quit attempt, or a nicotine replacement therapy (NRT) product in their most recent quit attempt. Former smokers who quit in the previous two years were asked similar questions in relation to their successful quit attempt.

Table 3 summarises data on medical advice and counselling advice/self-help material and NRT use for these current smokers and former smokers. There were no significant differences between current and former smokers on reported exposure to these cessation strategies. Approximately two-thirds of these current $(63.4 \%)$ and former smokers (64.5\%) reported they did not use quit assistance. More detailed information about NRT use has been presented elsewhere. ${ }^{22}$

\section{Reasons for quitting}

Current smokers (quit attempt in previous 12 months) were asked the main reason for their longest quit attempt in the past

Table 2: Quitting continuum levels: percentages of NSW and Californian current smokers (who were smoking 12 months before) in each level.

\begin{tabular}{|c|c|c|c|}
\hline $\begin{array}{l}\text { Quitting continuum } \\
\text { levela }^{\mathbf{a}}\end{array}$ & Level definitions ${ }^{b}$ & $\begin{array}{l}\text { NSW sample } \\
n=252 \\
\%\end{array}$ & $\begin{array}{l}\text { Californian sample } \\
n=10,552 \\
\%\end{array}$ \\
\hline 1. Pre-contemplation & $\begin{array}{l}\text { High addiction ( } \geq 15 \text { cigarettes/day), no quit attempt in last year, no intent } \\
\text { to change in six months }\end{array}$ & 13.5 & 17.9 \\
\hline 2. Contemplation ${ }^{c}$ & $\begin{array}{l}\text { High addiction and either limited quitting history ( } 1-6 \text { day quit attempt in the } \\
\text { last year) or intent to change }\end{array}$ & 15.5 & 9.3 \\
\hline 3. Earty preparation & High addiction and limited quitting history plus intent to change & 4.0 & 2.7 \\
\hline 4. Intermediate preparation & $\begin{array}{l}\text { Low addiction ( }<15 \text { cigarettes/day or occasional smoking) or a strong quitting } \\
\text { history ( } \geq 1 \text { year since became addicted or } \geq 1 \text { week in last year) }\end{array}$ & 36.1 & 35.1 \\
\hline 5. Advanced preparation & Both low addiction and strong quitting history & 31.0 & 34.9 \\
\hline \multicolumn{4}{|c|}{$\begin{array}{l}\text { (a) Full definitions and data in Pierce et al. }{ }^{27} \\
\text { (b) Smokers who have ever quit } \geq 1 \text { year since addicted are not categorised in levels 1-3, even if they fulfill other relevant criteria. } \\
\text { (c) } \chi^{2}=10.99, \rho=0.001 \text {. }\end{array}$} \\
\hline
\end{tabular}


year. Responses were not prompted. Responses that did not fit a pre-coded category were typed by interviewers and classified later by one researcher with checking by a second. Former smokers were asked the same question about their successful quit attempt. There was only one category, "desire to make quit attempt", where proportions of current and former smokers were significantly different $\left(\chi^{2}=21.80\right.$, $p=0.04$ ). Table 4 outlines the reasons nominated by respondents.

\section{Discussion}

The study confirms there is a high level of past and current quitting interest and behaviour among smokers. Approximately one-third (32.8\%) of current smokers had quit for at least one year in the past, similar to the proportion (39\%) reported in a Victorian study. ${ }^{23}$ The proportion $(61.0 \%)$ who had quit intentionally for at least one day in the last year was similar to a 2002 Californian estimate (62.1\%). ${ }^{21}$ However, the study proportion was significantly higher than that reported in a 1994 NSW study (43\%), which used a differently worded question to assess quit attempts ${ }^{24}\left(\chi^{2}=33.4, p<0.0001\right)$. The finding that nearly three-quarters $(73.9 \%$ ) of intentional quitters had relapsed within one month emphasises the need to encourage early use of relapse prevention strategies in this population.

Since older smokers were less likely to make a quit attempt, cessation efforts designed to motivate smokers over 40 years of age and to overcome their self-exemption ${ }^{25}$ and unrealistic optimism $^{26}$ seem important. Victorian ${ }^{23}$ and Californian ${ }^{21,27}$ data have shown a similar relationship between age and quitting behaviours.

In relation to quitting intentions, only $16.2 \%$ of the sample indicated they never expect to quit, which was significantly less than the proportion (24.1\%) reported in a 1989 South Australian study $^{28}\left(\chi^{2}=135.4, p<0.0001\right)$. Although the question wording used in the two studies was different, the results suggest there may have been an increase in quitting interest in Australia during the past decade. This complements the other finding above which indicated that the proportion of NSW smokers making a quit attempt may have increased since 1994.

The distribution of current smokers on the quitting continuum was similar to that in a 1996 random sample of Californian smokers, ${ }^{27}$ except for a significantly higher proportion in the contemplation category. In the 1990s, California was regarded as a model for tobacco control initiatives. More than two-thirds $(67.1 \%)$ of NSW smokers were in the two highest levels of the current smoking section of the quitting continuum. This indicates that tobacco control efforts appear to have been reasonably effective in maintaining a high level of quit interest among NSW smokers.

In contrast to quit attempts where age emerged as the sole predictor, the only predictor of being in levels 4 and 5 of the quitting continuum was educational attainment. Although some early research did not find a relationship between education and smoking behaviour change, ${ }^{29}$ recent studies have tended to emphasise the influence of socio-economic status and nicotine dependence on smoking and quitting behaviours. ${ }^{30-32}$

An Australian study concluded that socio-economic status affects cessation through social factors and that the association of education and cessation disappeared after adjusting for social environmental variables. ${ }^{33}$ However, the one social variable examined in this study, namely living with another smoker, did not predict quit attempts in the past year or position on the quitting continuum.

The proportion of smokers 26 years and older classified as hard-core in this NSW sample (5.5\%) was remarkably similar to that reported in a Californian study $(5.2 \%),{ }^{14}$ but almost half that in an English study (10\%). ${ }^{17}$ The higher prevalence in England may be due to less vigorous quit campaigns ${ }^{17}$ and/ or to social class differences. ${ }^{30}$ Based on the results of clinical trials, Irvin and Brandon ${ }^{13}$ argued that as more smokers quit, the population of remaining smokers may become progressively more difficult to treat. However, Jarvis et al. ${ }^{17}$ have speculated that declining smoking prevalence leads to a lower acceptability of smoking which may, in fact, reduce

\section{Table 4: Main reason for quit attempt nominated by current smokers who made a quit attempt in the previous 12 months and all former smokers: percentages.}

\begin{tabular}{|c|c|c|}
\hline $\begin{array}{l}\text { Main reason for } \\
\text { quit attempt }\end{array}$ & $\begin{array}{c}\text { Former } \\
\text { smokers } \\
n=400\end{array}$ & $\begin{array}{c}\text { Current } \\
\text { smokers } \\
n=153\end{array}$ \\
\hline \multicolumn{3}{|l|}{ Personal health concern } \\
\hline General health improvement or fitness & 35.8 & 32.7 \\
\hline $\begin{array}{l}\text { Specific health symptoms, problems } \\
\text { or hospitalisation }\end{array}$ & 19.0 & 22.9 \\
\hline Medical advice & 5.0 & 2.6 \\
\hline Pregnancy-related (females only) & 4.3 & 1.3 \\
\hline \multicolumn{3}{|l|}{ Personal attitude } \\
\hline Addiction concern/dislike & 6.8 & 7.2 \\
\hline $\begin{array}{l}\text { Lack of smoking enjoyment/aversion to } \\
\text { taste and smell }\end{array}$ & 4.2 & 2.0 \\
\hline Desire to make quit attempt ${ }^{\mathrm{a}}$ & 1.8 & 5.2 \\
\hline \multicolumn{3}{|l|}{ Social environment } \\
\hline Social/partner influence & 5.7 & 2.6 \\
\hline $\begin{array}{l}\text { Tobacco-related death/health problems } \\
\text { of other person }\end{array}$ & 2.0 & 0.7 \\
\hline Children's health/example & 1.8 & 2.0 \\
\hline Monetary cost & 8.0 & 13.1 \\
\hline Mass media campaigns ${ }^{\mathbf{b}}$ & 1.3 & 0 \\
\hline Other reason $^{b}$ & 1.0 & 4.6 \\
\hline Don't remember ${ }^{b}$ & 1.0 & 2.0 \\
\hline \multicolumn{3}{|l|}{ (a) $\chi^{2}=21.80, p=0.04$} \\
\hline
\end{tabular}


the prevalence of hard-core smoking. The very low fraction of hard-core smokers in NSW supports this position and suggests that quit campaigns do not appear to need substantial reorientation to target this small subpopulation.

Less than half (46.7\%) of current smokers who had visited a CP in the previous 12 months recalled any medical advice to quit during that period. These findings support the view that doctors need to reinforce their quit interventions at least annually and ensure all smokers are covered.

Only a minority of smokers who tried to quit in the previous 12 months reported using counselling/self-help materials (22.9\%) or nicotine replacement therapy NRT (32.7\%) to adjust to life without cigarettes. The limited use of cessation assistance demonstrates that most smokers attempt to quit on their own and mirrors the finding of a 1991 Canadian study. ${ }^{7}$ it is evident that even in a setting where NRT is available over-the-counter and well-publicised Quit lines exist, most NSW smokers choose to quit on their own. In the Canadian survey, many smokers appeared to be unaware of effective cessation methods and most underestimated their benefit. ${ }^{7}$ The offer of free NRT was most frequently mentioned by New York smokers (53\%) as the intervention that would motivate them to think seriously about stopping smoking. ${ }^{34}$ However, the effectiveness of NRT may be compromised when used over-the-counter without other assistance. ${ }^{22,35}$

The diverse range of responses given to the question about the main reason for quitting illustrates Chapman's point ${ }^{36}$ about the tendency to oversimplify explanations of declines in smoking prevalence. Clearly, personal health concerns (general and specific) are the commonest motivators, however attitudinal, environmental and cost reasons are also important, and there is likely to be interplay between these factors.

The 2001 National Drug Strategy Household Survey ${ }^{37}$ asked smokers who made any change to their smoking behaviour, including reducing intake or switching to 'lower tar/nicotine' brands, for their reasons. Unlike our methodology, a preprepared list was presented and more than one reason could be nominated. Personal health concerns were still nominated most frequently, however anti-smoking advertisements (26.4\%) were mentioned much more than in this sample (former smokers $1.3 \%$, current smokers $0 \%$ ). This difference emphasises the likely influence of question design on findings.

While these results endorse the value of a continued strong focus on health issues in quit campaigns, they also suggest that, for a substantial proportion of smokers, other motivators such as their negative personal attitudes to smoking and social environment influences may have more salience. If the Commonwealth Government increased the pitifully small fraction of its tobacco revenue devoted to tobacco control efforts, ${ }^{38}$ some of these funds could be directed towards interventions that targeted these less prominent motivators. The main limitations of this study include the cross-sectional design, the relatively small sample size of current smokers which limits the power of some analyses, and the reliance on selfreport. Some respondents may have offered socially desirable answers and there may be some problems related to recalling information, especially about events occurring up to two years ago in the case of former smokers.

\section{Conclusion}

NSW smokers remain a fertile target group for quit campaigns. Most smokers are making regular quit attempts, believe they will quit in the future and are in the intermediate or advanced preparation levels of the quitting continuum. ${ }^{12}$ Personal health concerns remain the main drivers of quit attempts, however other issues such as the cost of cigarettes could also be emphasised in media communications. Older smokers require special attention in quit campaigns and, although the percentage of defined hard-core smokers is very low, the larger proportion of smokers $(16.2 \%)$ who say they never expect to quit may require tailored intervention.

The findings also highlight the importance not just of motivating smokers to make a quit attempt, but of reducing the high rates of relapse in the immediate post-quit period. Relapse rates could be decreased by encouraging greater use of self-help materials, NRT and Quit lines. Proactive phone counselling may be a useful strategy in promoting more assisted quit attempts. ${ }^{39}$

\section{Acknowledgements}

Thanks to Dr Patrick McElduff, who undertook many of the preliminary analyses. This paper was prepared by the Centre for Health Research \& Psycho-oncology (CHeRP). CHeRP is funded by The Cancer Council NSW and the University of Newcastle. This study was also supported by funding from NSW Health through the Hunter Medical Research Institute. The views expressed are not necessarily those of the Cancer Council NSW.

\section{References}

1. Giardina TD, Hyland A, Bauer UE, Cummings KM. Which population-based interventions would motivate smokers to think seriously about stopping smoking? Am I Health Promot. 2004;18:405-8.

2. The Smoking Cessation Clinical Practice Guideline Panel and Staff. The Agency for Health Care Policy and Research Smoking Cessation Clinical Practice Cuideline. I Am Med Assoc. 1996;275:1270-80.

3. Walsh RA, Sanson-Fisher RW. Encouraging Stopping Smoking. Ceneva (CHE): Department of Mental Health and Substance Dependence, World Health Organization; 2001.

4. Dwyer T, Pierce JP, Hannan CD, Burke N. Evaluation of the Sydney "Quit for Life" anti-smoking campaign. Part 2. Changes in smoking prevalence. Med / Aust. $1986 ; 144: 344-7$

5. Tan N, Wakefield $M$, Freeman J. Changes associated with the National Tobacco Campaign: results of the second follow-up survey. In: Hassard K, editor. Australia's National Tobacco Campaign Evaluation Report. Vol Two. Canberra (AUST): Commonwealth of Australia; 2000. p. 21-76.

6. Laforge RG, Velicer WF, Richmond RL., Owen N. Stage distributions for five health behaviours in the United States and Australia. Prev Med. 1999;28:61-74. 
7. Pederson LL, Bull SB, Ashley MJ, MacDonald JK. Quitting smoking: why, how and what might help. Tob Control. 1996;5:209-14.

8. Prochaska JO, DiClemente CC, Norcross JC. In search of how people change Applications to addictive behavior. Am Psychol. 1992;47:1102-4

9. Etter)-F, Sutton S. Assessing 'stage of change' in current and former smokers. Addiction. 2002;97:1171-82

10. Farkas AJ, Pierce JP, Zhu S-H, Rosbrook B, Gilpin EA, Berry C, et al. Addiction versus stage of change models in predicting smoking cessation. Addiction. 1996;91:1271-80.

11. Carlson LE, Taenzer P, Kopmans J, Casebeer A. Predictive value of aspects of the Transtheoretical Model on smoking cessation in a community-based, large-group cognitive behavioural program. Addict Behav. 2003;28:725-40.

12. Pierce IP, Farkas AJ, Cilpin EA. Beyond stages of change: the quitting continuum measures progress towards successful smoking cessation. Addiction. 1998;93:277 86.

13. Irvin JE, Brandon TH. The increasing recalcitrance of smokers in clinical trials Nicotine Tob Res. 2000;2:79-84

14. Emery S, Gilpin EA, Ake C, Farkas Al, Pierce JP. Characterising and identifying "hard-core" smokers: implications for further reducing smoking prevalence. Am J Public Health. 2000;90:387-94.

15. Warner KE, Burns DM. Hardening and the hard-core smoker; concepts, evidence, and implications. Nicotine Tob Res. 2003;5:37-48.

16. Hughes JR, Brandon TH. A softer view of hardening. Nicotine Tob Res 2003;5:961-2.

17. Jarvis MJ, Wardle J, Waller ], Owen L. Prevalence of hardcore smoking in England, and associated attitudes and beliefs: cross sectional study. $\mathrm{Br}$ Med J. 2003;326:1061-5

18. National Health Data Dictionary. Version 8.0. Canberra (AUST): Australian Institute of Health and Welfare; 1999.

19. Australian Bureau of Statistics. NSW Community Profiles, 1996 Census Data. Canberra (AUST): ABS; 1996.

20. Hill D), White VM, Scollo MM. Smoking behaviours of Australian adults in 1995 trends and concerns. Med / Aust. 1998;168:209-13.

21. Gilpin EA, White MM, White VM, Distefan JM, Trinidad DR, James L, et al. Tobacco Control Successes in California. A Focus on Young People. Results from the California Tobacco Surveys, 1990-2002. La Jolla (CA): University of California, San Diego; 2003.

22. Paul CL, Walsh RA, Girgis A. Nicotine replacement therapy products over the counter real-life use in the Australian community. Aust N Z J Public Health. 2003;27:491-5.

23. Trotter $\mathrm{L}$, Inglis $\mathrm{G}$. Key findings of the 2000 and 2001 population surveys. In: Letcher L, Trotter L, editors. Quit Victoria Research and Evaluation Studies: Number 11. Melbourne (AUST): Centre for Behavioural Research in Cancer; 2003.
24. Graham-Clarke P, Nathan S, Stoker L, Bauman A, Wise M. NSW Health Promotion Survey 1994. Best practice for reducing the prevalence of smoking in the Areas of NSW. Sydney (AUST): NSW Health Department, Health Promotion Branch; 1996. State Health Publication No.: (HP) 96-0006.

25. Oakes W, Chapman S, Borland R, Balmford I, Trotter L. "Bulletproof skeptics in life's jungle": which self-exempting beliefs about smoking most predict lack of progression towards quitting? Prev Med. 2004;39:776-82.

26. Weinstein ND, Marcus SE, Moser RP. Smokers' unrealistic optimism about their risk. Tob Control. 2005;14:55-9.

27. Pierce IP, Gilpin EA, Emery SL, Farkas AJ, Zhu SH, Choi WS, et al. Tobacco Control in California: Who's Winning the War? An evaluation of the Tobacco Control Program, 1989-1996. La Jolla (CA): University of California, San Diego; 1998.

28. Owen N, Wakefield M, Roberts L, Esterman A. Stages of readiness to quit smoking: population prevalence and correlates. Health Psychol. 1992;11:413-17.

29. Eisinger RA. Psychosocial predictors of smoking behaviour change. Soc Sci Med. $1972 ; 6: 137-44$

30. Jefferis $B J M H$, Power $C$, Graham $H, M a n o r ~ O$. Changing social gradients in cigarette smoking and cessation over two decades of adult follow-up in a British birth cohort. J Public Health. 2004;26:13-18

31. Chandola T, Head J, Bartley M. Socio-demographic predictors of quitting smoking: how important are household factors? Addiction. 2004;99:770-7.

32. Broms U, Silventoinen K, Lahelma E, Markku K, Kaprio J. Smoking cessation by socio-economic status and marital status: the contribution of smoking behaviour and family background. Nicotine Tob Res. 2004;6:447-55.

33. Siahpush $M$, Borland $R$, Scollo $M$. Factors associated with smoking cessation in a national sample of Australians. Nicotine Tob Res. 2003;5:597-602.

34. Hammond D, McDonald PW, Fong GT, Borland R. Do smokers know how to quit? Knowledge and perceived effectiveness of cessation assistance as predictors of cessation behaviour. Addiction. 2004;99:1042-8

35. Pierce JP, Cilpin E, Farkas AJ. Nicotine patch use in the general population: results from the 1993 Californian Tobacco Survey. I Nat/ Cancer Inst. 1995;87:87-93.

36. Chapman $S$. Unravelling gossamer with boxing gloves: problems in explaining the decline in smoking. Br Med J 1993; 307: 429-432.

37. Australian Institute of Health and Welfare. 2001 National Drug Strategy Household Survey: Detailed Findings. Canberra (AUST): AlHW; 2002. AlHW Drug Statistics Series No. 11, Catalogue No.: PHE41.

38. Doran CM, Walsh RA. Tobacco industry in Australia: still a profitable venture? Aust N Z) Public Health. 2003;27:559-60.

39. Paul CL., Wiggers J, Daly JB, Green S, Walsh RA, Knight ), et al. Direct telemarketing of smoking cessation interventions: Will smokers take the call? Addiction. 2004;99:907-13.

\section{Authors}

Raoul A. Walsh, Christine L. Paul, Flora Tzelepis, Centre for Health Research \& Psycho-oncology (CHeRP), The Cancer Council New South Wales/University of Newcastle, New South Wales

Elizabeth Stojanovski, Health Behaviour Research Collaboration, Hunter Medical Research Institute, University of Newcastle New South Wales

Correspondence

Dr Raoul Walsh, Centre for Health Research \& Psycho-oncology (CHeRP), Locked Bag 10, Wallsend, New South Wales 2287. Tel: (02) 4924 6372; fax: 024924 6208; e-mail:Raoul.Walsh@newcastle.edu.au 